\title{
Fuel Pellets from Fine Paper Mill Sludge Supplemented by Sawdust and by Refined Recovered Lubricating Oil
}

\author{
Ishaq Ahmad, ${ }^{a}$ Min-Seok Lee, ${ }^{\mathrm{b}}$ Ho-Kyung Goo, ${ }^{\mathrm{b}}$ Chang-Yeong Lee, ${ }^{\mathrm{b}}$ Jeong-Heon Ryu, \\ and Chul-Hwan Kim ${ }^{\mathrm{b}}$
}

Fine paper mill sludge (FPMS) disposal has emerged as a problem since the dumping of FPMS was banned. This study investigated the effects of adding a refined recovered lubricating oil (ion-refined oil) to FPMS pellets to increase its heating value and combustion time and decrease ash content and ignition time. Fuel pellets were prepared in three conditions, C-1, C-2, and C-3. In C-1, ion-refined oil was added to FPMS to examine its burning capability. In C-2, two types of pellets were produced mixing sawdust and FPMS ratios of 25:75 and 50:50. A ratio of 50:50 was selected for C-3, to which the ion-refined oil was added in different ratios. The quality of the energy fuel pellets was determined using proximate and ultimate analyses, except for chlorine content, which was determined through liquid ion chromatography. The properties of fuel pellets were determined and compared with national standards. It was confirmed that the results for pellets at a ratio of $50: 50$ with $10 \%$ and $15 \%$ ion-refined oil were acceptable, because these results were comparatively similar to the standards. Finally, it was concluded that ion-refined oil was an effective additive to FPMS to increase the heating value for energy demand and lower the ash content.

Keywords: Fine paper mill sludge (FPMS); Pellets; Ion-refined oil; Heating value; Ash content; Ignition

Contact information: a: Department of Forest Products, Gyeongsang National University, 52828, Jinju, Korea; b: Department of Forest Products, IALS, Gyeongsang National University, 52828, Jinju, Korea; *Corresponding author: jameskim@gnu.ac.kr

\section{INTRODUCTION}

Utilization of paper mill sludge (PMS) for energy purposes has attracted continuous consideration over the past few decades. The paper industry is a strategic and economic growth sector for the development of the country (Coimbra et al. 2015). According to a report from the Confederation of European Paper Industries (CEPI) in 2016, globally the total production of paper is 408 million tons, leading to approximately 95 million tons of PMS generation (Lee et al. 2017). The escalating global production of PMS is expected to increase over the next 50 years by $48 \%$ to $86 \%$ over the current level. The London Convention was created to preserve the world's marine pollution in 1975, but the ocean dumping of PMS has continued until recently. Today, it has turned to landfilling due to the strict regulations on ocean dumping of PMS (Likon and Trebše 2012; Abdullah et al. 2016; Lee et al. 2017). The most suitable alternative method is through thermal processes, such as combustion, which have been explored in the U.S. Patent No. 5302254 (1994), which describes a management option for the conversion of amplified untapped sludge to solid fuel pellets for energy recovery (Budzyń and Tora 2016; Monte et al. 2009). Nosek et al. (2017) reported that PMS has several limitations: it has no fixed carbon, low volatile matter, high ash content, and low calorific value when pelletized with sawdust for energy 
utilization. Several studies of PMS pelletization have been conducted. The appropriate amount is between $10 \%$ and $20 \%$ PMS content mixed with wheat straw to produce high quality fuel pellets (Budzyń and Tora 2016; Nosek et al. 2017; Matúš et al. 2018). Ash is the inorganic solid residue left after the solid fuel is completely burned (Demirbaş 2007). The ash content varies depending on the inorganic matter present in the PMS. The basic major ash-forming components are silica $(\mathrm{Si})$, aluminum $(\mathrm{Al})$, iron $(\mathrm{Fe})$, calcium $(\mathrm{Ca})$, sodium $(\mathrm{Na})$, magnesium $(\mathrm{Mg})$, potassium $(\mathrm{K})$, and manganese $(\mathrm{Mn})$. Ash-forming minor elements include cadmium $(\mathrm{Cd})$, chromium $(\mathrm{Cr})$, copper $(\mathrm{Cu})$, nickel $(\mathrm{Ni})$, zinc $(\mathrm{Zn})$, arsenic (As), mercury ( $\mathrm{Hg}$ ), and lead (Pb) (Lindström et al. 2010; Chandrasekaran et al. 2012; Zevenhoven et al. 2012). The high grade of the fuel pellets for energy demand mainly depends on their chemical composition. The major chemical constituents in solid fuel pellets are $\mathrm{C}, \mathrm{H}, \mathrm{N}, \mathrm{O}$, and $\mathrm{Cl}$ : carbon ( $45 \%$ to $50 \%$ of the mass), hydrogen (approximately $6 \%$ ), nitrogen (less than 1\%), oxygen (approximately $40 \%$ to $50 \%$ ), and chlorine (less than 2\%) (Basu 2010; Sommersacher et al. 2012; Siddiqui et al. 2019). The quality of fuel pellets is mainly determined by some important key parameters, including ash content, heating value, amount of fines, mechanical durability, and bulk density (Jenkins et al. 1998; Lehtikangas 2001). The basic and most important parameters, which are well defined in the American Society for Testing Materials (ASTM) and International Organization for Standardization (ISO) standards, are used to decide the applicability of solid fuels in the market (Tarasov et al. 2013; Kang et al. 2018; Mock et al. 2018). However, the use of PMS for energy demand and its applications are not straightforward. On the basis of the problems highlighted above related to the reuse of PMS for energy demand, solid fuel with additives will ensure satisfaction of the required energy demand from this waste (Berghel et al. 2013). To address the use of such waste to fulfill energy demand, the exploration of new types of additives has become a useful and attractive direction for modern research targets in the last two decades. Thus far, different types of additives have been tested, including lignin as a co-binder and to increase the heating value (Demirbaş 2001; Lehtikangas 2001; Demirbas 2007), proteins, molasses, corn starch, coal, bentonite, fossil fuel, bio-oil, engine oil, and cooking vegetable oil (Narra et al. 2010; Misljenovic et al. 2014; Ward et al. 2014; Coimbra et al. 2015; Jittabut 2015; Kang et al. 2018). Generally, the addition of bio-oil, cooking oil, engine oil, and fossil fuel has been shown to have positive effects on factors such as ignition, combustion, higher heating value, and to minimize environmental problems (Misljenovic et al. 2014).

The oil considered in this work was an ionic refined oil produced by precipitating, separating, and dehydrating foreign substances in used lubricating oil by introducing various coagulants containing anions (Bridjanian and Sattarin 2006). Each country's waste management acts stipulate the quality standards for recycled fuel oil such as carbon content, moisture, ash, sulfur, and flash point. Accordingly, the used oil recycling industry recovers base oil with a certain quality, which needs to be upgraded. After the fast pyrolysis process, ion-refined oil contains moisture content below $5 \%, 0.66 \%$ ash, $0.26 \%$ sulfur, $0.01 \%$ nitrogen, and a viscosity of $950 \mathrm{cP}$ (Bae and Kwon 2006). Ion-refined oil is abundant in aldehydes, ketones, and phenolic compounds. The organic and inorganic composition of a typical ion-refined oil was reported as $\mathrm{Zn}(31.52 \mathrm{mg} / \mathrm{kg}), \mathrm{Ni}(35.61 \mathrm{mg} / \mathrm{kg})$, and $\mathrm{Ba}(12.82$ $\mathrm{mg} / \mathrm{kg}$ ), while its heating value was $42,100 \mathrm{kcal} / \mathrm{kg}$. Ion-refined oil cannot be used as fuel due to its high viscosity and high oxygen content. However, it has been successfully used as an additive to sewage sludge to increase its heating value. Therefore, ion-refined oil has the potential to increase the quality of solid fuel pellets. Based on the above statements, the aim of this study was to recycle fine paper mill sludge (FPMS) for energy demand with 
ion-refined oil as an additive. The major limiting factors of energy fuel pellets from FPMS are its low calorific value, high ash content, high ignition time, and low combustion time. Ion-refined oil was used as an additive with FPMS and sawdust in different ratios to increase the heating value, decrease ignition time, increase combustion time, and reduce the ash content. To the best of the authors' knowledge, the present study is the first to explore the performance of ion-refined oil as an additive to FPMS during pelletization. The results of the present study will help to provide and develop high quality fuel pellets from FPMS and to become useful information that can solve the problem of PMS faced by the paper industry.

\section{EXPERIMENTAL}

\section{Raw Materials}

For this experimental study, a dewatered FPMS in the form of compressed agglomerates with a moisture content of 53\% to 63\% was delivered from the Jinju Moorim paper mill (Moorim Paper Co., Ltd., Jinju, Korea) to the research team. FPMS accumulates during the production of coated wood-free paper and is mainly composed of $\mathrm{CaCO}_{3}$ and cellulosic fine particles. Initially, the FPMS was dried naturally by sunlight for $72 \mathrm{~h}$. After drying the FPMS until its moisture content was lower than 5\%, it was ground and pulverized to a small particle size (Table 1) appropriate for the pelletizing process. Dry raw mixed sawdust of rubber wood (Hevea brasiliensis) and red-pine wood (Zanthoxylum coreanum) was collected from a local furniture workshop. The raw mixed sawdust was milled to within the particle size shown in Table 1 . The particle size distribution of the raw materials was measured based on ISO 17830 (2016). Woody biomass as raw material makes grinding more efficient and has a positive effect during the fuel pellets' combustion. Dry ground FPMS is made up of a high-volume ratio of cellulose fibers, which has a positive effect on the mechanical properties of the fuel pellets. The FPMS cellulose fibers are comparatively free of lignin, while pure sawdust contains a certain amount of lignin, which improves the mechanical properties of fuel pellets. The ion-refined oil additive was chosen based on a literature review of articles because this additive has a high heating value (Bae and Kwon 2006). Ion-refined oil is a renewable fuel oil produced by precipitating, separating, and dehydrating foreign substances in waste oil by introducing various anionic coagulants containing anions. The oil was donated from Moorim P\&P Co., Ltd. in Ulsan, Korea.

Table 1. Feed Stock Raw Materials' Particle Size Distribution

\begin{tabular}{|c|c|c|}
\hline \multicolumn{3}{|c|}{ Proportion by Weight (\%) } \\
\hline Particle size $(\mathbf{m m})$ & Sawdust & Fine Paper Mill Sludge \\
\hline$>4.00$ & 1.18 & 0 \\
\hline $2.00<4.00$ & 37.61 & 4.13 \\
\hline $1.00<2.00$ & 39.91 & 25.97 \\
\hline $0.50<1.00$ & 12.25 & 18.17 \\
\hline$<0.50$ & 8.35 & 51.73 \\
\hline
\end{tabular}




\section{Pelletizing Process}

Pellets were prepared through a laboratory-scale custom-made pelletizer equipped with a flat die with a hole diameter of $8 \mathrm{~mm}$. During pellet production, the ambient temperature in the chamber was about $85{ }^{\circ} \mathrm{C}$, and the pelletizing process generated heat that maintained the temperature of the operating die at 110 to $120{ }^{\circ} \mathrm{C}$. The clearance between the roll and the die was approximately 0.1 to $0.3 \mathrm{~mm}$ (about $50 \mathrm{MPa}$ ). The moisture content of the raw materials was adjusted to the range 12 to $15 \%$ for pellet production. Once the pelleting process had reached a stable state, a sample of $12 \mathrm{~kg}$ of each pellet mixture was used for pelletization. Fuel pellets with a diameter of $8 \mathrm{~mm}$ and an average length of $29 \mathrm{~mm}$ were produced. All eleven samples of pellets were stored at 20 ${ }^{\circ} \mathrm{C}$ and $55 \%$ relative humidity in a laboratory for 10 days after their production to reach a stable state before testing.

\section{Proximate Analysis}

Proximate analysis of the samples was accomplished according to the methods set out by the ASTM (Chandrasekaran et al. 2012; Poddar et al. 2014). The moisture content was determined using ASTM E871-82 (2019) test methods for the direct moisture content analysis of wood and wood-based materials. A $10 \mathrm{~g}$ sample was heated in an oven at $103 \pm 5$ ${ }^{\circ} \mathrm{C}$ for $24 \mathrm{~h}$. Ash content was determined according to ASTM D1102-84 (2013) for analysis of ash content, $2 \mathrm{~g}$ of the pulverized sample was burned in a ceramic crucible for $3 \mathrm{~h}$ at 550 ${ }^{\circ} \mathrm{C}$ using a muffle furnace. The percentage of volatile matter was determined according to ASTM D3175-20 (2020). A total of $2 \mathrm{~g}$ of the pulverized sample was burned in a ceramic crucible with a lid cover, at a temperature of $950 \pm 13{ }^{\circ} \mathrm{C}$ for $6 \mathrm{~min}$, and then weighed. Three replicates were analyzed for each sample. The percentage of fixed carbons was calculated as the difference between 100 and the sum of moisture content, volatile matter, and ash content.

\section{Ultimate Analysis}

The ultimate analysis of raw materials and prepared fuel pellet samples was performed according to ASTM D5373-16 (2016), which is the standard method for the analysis of coal and inhomogeneous materials, using a Macro Elemental Analyzer made in Langenselbold, Germany (Vario MACRO cube, Elementar Analysensysteme GmbH) working under CHNS mode. To determine the chlorine content, samples were prepared using a modified version of the bomb washing method in the United States Environmental Protection Agency (EPA) SWP-846 Method 5050 (1994), and it was then determined through ion chromatography (930 Compact IC Flex; Swiss, Metrohm, Herisau, Switzerland) (Chandrasekaran et al. 2012; Toscano et al. 2013).

\section{Higher Heating Value (HHV) and Lower Heating Value (LHV)}

The HHV of the raw materials and fuel pellets produced was measured following the ASTM E2618-13 (2019) standard test method for gross calorific value of coal using a 1138 oxygen combustion bomb calorimeter (Parr-6400; Parr Instrument Company, Moline, IL, USA). The LHV of fuel pellets was obtained using Dulong's formula (Demirbaş 2001; Demirbas 2007). The composition of lignocellulosic sawdust substrate lignin, cellulose, and hemicellulose was determined according to the TAPPI T203 cm-99 (1999) method (Adeeyo et al. 2015). 


\section{Bulk Density}

The bulk density is mainly dependent on the density of particles and the pore volume. The higher the bulk density, the higher the energy density, and the lower the transport and storage costs. The bulk density of fuel pellets was determined according to ISO 17828 (2015). The densities of the raw material and the pellets were measured separately using different methods. Specifically, for the raw material (powder type), bulk density was measured using a 500-mL density cup. For the pellets, bulk density is a parameter that is easy to determine and is the ratio of the mass and total volume of the fuel pellets. The average index of bulk density for each sample was calculated from three measurements.

\section{Durability}

The mechanical durability of the fuel pellets was determined according to ISO 17831-1 (2015). In a laboratory-scale tumbler taster, $500 \mathrm{~g}$ of fuel pellets were tested after 500 revolutions. The treated sample was sieved using round screen holes of $3.15 \mathrm{~mm}$ according to ISO 3310-2 (2013). The percentage of unbroken pellets remaining was weighed and recorded for the mechanical durability index. Three replicates were analyzed for each sample.

\section{Fines Contents}

Fine particles of fuel pellets (sample) are particles (impurities) smaller than 3.15 $\mathrm{mm}$, as well as dust in the sample. According to the standard method, the required apparatus for determination of fine particles comprises a sieve with a dimension of $3.15 \mathrm{~mm}$, an analytical scale, and a measuring pot. Fines content of fuel pellets was determined according to ISO 3310-2 (2013). For every determination of fine particles, it is necessary to take at least three measurements.

\section{Ignition and Combustion}

This experiment was conducted following a study of the literature to determine the ignition and combustion time of the fuel pellets. The ignition and combustion experiment were performed according to laboratory-scale available facilities. For single fuel pellet burning, a Prince micro torch lighter (GT-3000; Prince, Matsudo, Japan) was used, and each sample was burned in an aluminum foil petri dish. A digital camera (EOS 800D; Canon, Tokyo, Japan) was used for the direct quantitative and qualitative analyses of ignition and combustion time. During the ignition and combustion of the pellets, a highspeed camera was not essential, because single pellets only burn for a short period. To maintain an identical background, all the ignition and combustion experiments were performed in a dark room.

\section{RESULTS AND DISCUSSION}

Table 2 summarizes the results of proximate and ultimate analysis on the pellets, and chemical composition of the sawdust pellets along with of the pellet images made of $100 \%$ FPMS and wood sawdust, respectively. As the ash content of FPMS was very high, about $52 \%$, the remaining component could be estimated to be cellulose fibers. Sawdust pellets appeared similar to the chemical properties of common lignocellulosic biomass. 
FPMS pellets contained almost no fixed carbon, and the carbon content was only about half that of the sawdust pellets. In addition, the calorific value was inevitably low due to a very high ash content and a very low volatile matter. Nosek et al. (2017) also reported that PMS had several limitations as a fuel for the same reason.

Table 2. Basic Properties of FPMS and Sawdust

\begin{tabular}{|c|c|c|}
\hline & $\begin{array}{l}\text { Pellets from Fine Paper Mill } \\
\text { Sludge }\end{array}$ & Sawdust Pellets \\
\hline Pellet images & & \\
\hline \multicolumn{3}{|c|}{ Proximate Analysis (wt\%) } \\
\hline Moisture content (MC) & $6.17 \pm 0.29$ & $7.19 \pm 0.62$ \\
\hline Ash content $(\mathrm{ASH})$ & $51.52 \pm 0.90$ & $0.47 \pm 0.47$ \\
\hline Volatile matter (VM) & $41.62 \pm 0.10$ & $73.21 \pm 0.66$ \\
\hline Fixed carbon (FC) & $0.70 \pm 0.06$ & $19.13 \pm 0.01$ \\
\hline \multicolumn{3}{|c|}{ Ultimate Analysis (wt\%) } \\
\hline Carbon $(\mathrm{C})$ & 22.85 & 45.03 \\
\hline Hydrogen $(\mathrm{H})$ & 3.66 & 6.44 \\
\hline Nitrogen $(\mathrm{N})$ & 2.25 & 0.19 \\
\hline Sulfur & 0.85 & 0.04 \\
\hline Oxygen (by difference) & 17.25 & 42.33 \\
\hline Chlorine & 0.89 & 1.45 \\
\hline High heating value ( $\mathrm{MJ} / \mathrm{kg}$ ) & 7.54 & 18.25 \\
\hline \multicolumn{3}{|c|}{ Fiber Analysis (wt\%) } \\
\hline Lignin & - & 17.1 \\
\hline Cellulose & - & 65.19 \\
\hline Hemicellulose & - & 13.45 \\
\hline Extractives & - & 4.26 \\
\hline
\end{tabular}

For C-1, FPMS pellets had low carbon and oxygen content compared to sawdust pellets, so it was confirmed that the ash content was high (Table 3). However, it was confirmed that the carbon content and the oxygen content increased as the ion-refined oil was added to the sludge. It was assumed that the carbon content of the pellets increased as the amount of ion refined oil, which has a higher carbon content, increased. The FPMS contained low levels of volatile matter, but the addition of ion-refined oil dramatically increased the content of volatile matter and reactivity as fuel for fast burning of the fuel 
pellets. The volatile materials are closely related to the capability of the ignition and combustion of a fuel. If the amount of volatile matter increases, the initial ignition becomes faster, but there is a disadvantage that the duration of combustion becomes short (Obernberger and Thek 2004).

Table 3. Properties of FPMS Pellets Mixed with Ion-Refined Oil

\begin{tabular}{|c|c|c|c|c|c|}
\hline C-1 & SD $^{*}$ & FPMS & IRO-10 & IRO-20 & IRO-30 \\
\hline MC (\%) & 2.51 & 6.63 & 7.82 & 8.26 & 8.63 \\
\hline VM (\%) & 73.84 & 40.74 & 43.05 & 45.40 & 51.59 \\
\hline Ash (\%) & 4.48 & 52.30 & 40.15 & 36.66 & 28.83 \\
\hline FC (\%) & 19.17 & 0.33 & 8.98 & 9.68 & 10.95 \\
\hline C (\%) & 45.07 & 23.41 & 28.25 & 31.86 & 34.43 \\
\hline H (\%) & 6.57 & 2.90 & 3.83 & 4.41 & 4.79 \\
\hline O (\%) & 42.34 & 18.03 & 24.37 & 24.05 & 28.63 \\
\hline N (\%) & 0.42 & 2.40 & 2.14 & 1.97 & 1.92 \\
\hline S (\%) & 0.50 & 0.96 & 1.27 & 1.05 & 1.40 \\
\hline Cl (\%) & 1.49 & 0.91 & 1.16 & 0.83 & 0.74 \\
\hline $\begin{array}{c}\text { Bulk Density } \\
\left.\text { (kg/m }{ }^{3}\right)\end{array}$ & 630.04 & 837.98 & 811.22 & 806.53 & 790.25 \\
\hline $\begin{array}{c}\text { Fines } \\
\text { Content (\%) }\end{array}$ & 0.08 & 0.07 & 0.18 & 0.12 & 0.14 \\
\hline
\end{tabular}

*: SD: Sawdust, FPMS: Fine paper mill sludge, IRO: ion-refined oil, MC: Moisture content, VM: Volatile material, FC: Fixed carbon, C: Carbon, H: Hydrogen, O: Oxygen, N: Nitrogen, S: Sulfur, and $\mathrm{Cl}$ : Chlorine

Fixed carbon content should be considered as the prime energy-producing factor for combustion and residue after devolatilization (Poddar et al. 2014; Basu 2018). Initially, FPMS pellets had only a small amount of fixed carbon, but the addition of ion-refined oil remarkably increased the fixed carbon content. It was confirmed that the carbon and oxygen content increased as the ion-refined oil was added, resulting in a decrease in ash content and an increase in volatiles content. At the same time, the bulk density was additionally increased compared to the sawdust pellets. The increased amount of fixed carbon in the fuel pellet was advantageous because the combustion duration was longer.

The primary components required for the combustion process are carbon, hydrogen, and oxygen. The content of carbon, hydrogen, and oxygen in FPMS was minimal compared to that of wood sawdust due to the high ash content, but it began to increase with the addition of ion-refined oil. This means that it is difficult to have efficient fuel characteristics with FPMS alone. Therefore, it is necessary to improve the fuel efficiency of FPMS using supplements such as ion-refined oil.

Sulfur and nitrogen should be considered as harmful emissions of $\mathrm{SO}_{\mathrm{x}}$ and $\mathrm{NO}_{\mathrm{x}}$ to the environment. These components, such as sulfur and nitrogen, are used in wastewater treatment for sludge precipitation or microbial activity control. More sulfur and nitrogen in pellets were detected in FPMS than in wood sawdust. It was assumed that these elements 
came from a wastewater treatment in the papermaking process. As ion-refined oil was added, the content of sulfur and nitrogen in FPMS decreased.

The bulk density of FPMS pellets increased approximately 33\% over that of sawdust pellets. It was considered that the inorganic filler particles constituting FPMS increased the bulk density of the pellets.

The chlorine content of FPMS is commonly converted to gaseous form to make $\mathrm{HCl}$ and $\mathrm{Cl}_{2}$ (Lehtikangas 2001; Carroll and Finnan 2012). The chlorine content in FPMS was detected less than in wood sawdust and gradually decreased with the addition of ionrefined oil.

Therefore, since FPMS pellets having an excessive ash content were not desirable, mixing of ion-refined oil was required to lower the ash content and increase the carbon content, thereby improving its value as a fuel. In addition, ionic refined oil additionally contributed to reducing the proportion of sulfur, chlorine, and nitrogen, which can cause problems in the boiler or atmosphere.

Table 4 shows the results of proximate analysis and ultimate analysis when sawdust was mixed with FPMS. As the amount of sawdust increased, fixed carbon in the pellets increased, and harmful elements, such as sulfur, chlorine, and nitrogen, decreased. Even if sawdust was added, there was no noticeable change in bulk density.

Table 4. Properties of FPMS Pellets with Sawdust

\begin{tabular}{|c|c|c|c|c|}
\hline C-2 & SD & FPMS & $\mathbf{2 5 : 7 5}$ & $\mathbf{5 0 : 5 0}$ \\
\hline $\mathrm{MC}(\%)$ & 2.51 & 6.63 & 6.63 & 6.89 \\
\hline $\mathrm{VM}(\%)$ & 73.84 & 40.74 & 39.40 & 46.28 \\
\hline Ash (\%) & 4.48 & 52.30 & 44.83 & 35.78 \\
\hline $\mathrm{FC} \mathrm{( \% )}$ & 19.17 & 0.33 & 9.47 & 11.72 \\
\hline $\mathrm{C}(\%)$ & 45.07 & 23.41 & 29.17 & 34.13 \\
\hline $\mathrm{H}(\%)$ & 6.57 & 2.90 & 4.34 & 4.87 \\
\hline $\mathrm{O}(\%)$ & 42.34 & 18.03 & 32.15 & 37.41 \\
\hline $\mathrm{N}(\%)$ & 0.42 & 2.40 & 1.61 & 1.22 \\
\hline $\mathrm{S}(\%)$ & 0.50 & 0.96 & 1.06 & 0.81 \\
\hline $\mathrm{Cl}(\%)$ & 1.49 & 0.91 & 0.66 & 0.68 \\
\hline $\begin{array}{c}\text { Bulk Density } \\
\left(\mathrm{kg} / \mathrm{m}^{3}\right)\end{array}$ & 630.04 & 837.98 & 853.35 & 844.03 \\
\hline Fines Content (\%) & 0.08 & 0.07 & 0.08 & 0.08 \\
\hline
\end{tabular}

Table 5 shows the results of proximate analysis and ultimate analysis when ionrefined oil was added to the pellets in which FPMS and sawdust were mixed at 50:50. The addition of ion-refined oil contributed to the increase of the amount of the fixed carbon in pellets made from FPMS and sawdust. It was found that the ion-refined oil negatively affected the bulk density of pellets made from FPMS and sawdust.

The HHV expresses the higher energy output from solid fuel. The HHV is one of the most important unit factors for quality determination of fuel pellets, which decides the applicability and use of solid fuels as one of the environmentally friendly fuels. The HHV has a direct relationship with carbon, hydrogen, and sulfur concentration but an indirect relationship with nitrogen and oxygen concentration (Gravalos et al. 2010). The LHV is determined by excluding the heat of vaporization of the water from HHV (Tarasov et al. 2013). This is because energy involved in the evaporation of water is not released as heat. 
Table 5. Properties of FPMS Pellets Prepared from FPMS and Sawdust Mixed at 50:50

\begin{tabular}{|c|c|c|c|c|c|c|}
\hline $\mathbf{C - 3}$ & SD $^{*}$ & FPMS $^{*}$ & IRO-5 & IRO-10 & IRO-15 & IRO-20 \\
\hline $\mathrm{MC}(\%)$ & 2.51 & 6.63 & 6.26 & 6.68 & 6.81 & 6.74 \\
\hline $\mathrm{VM}(\%)$ & 73.84 & 40.74 & 49.85 & 62.06 & 66.30 & 67.62 \\
\hline Ash (\%) & 4.48 & 52.30 & 29.05 & 15.70 & 8.49 & 6.82 \\
\hline $\mathrm{FC} \mathrm{( \% )}$ & 19.17 & 0.33 & 14.84 & 15.56 & 18.41 & 18.83 \\
\hline $\mathrm{C}(\%)$ & 45.07 & 23.41 & 36.12 & 38.38 & 40.65 & 42.19 \\
\hline $\mathrm{H}(\%)$ & 6.57 & 2.90 & 5.31 & 5.32 & 6.11 & 6.25 \\
\hline $\mathrm{O}(\%)$ & 42.34 & 18.03 & 24.96 & 38.09 & 42.92 & 42.92 \\
\hline $\mathrm{N}(\%)$ & 0.42 & 2.40 & 1.28 & 1.26 & 1.08 & 1.07 \\
\hline $\mathrm{S}(\%)$ & 0.50 & 0.96 & 0.83 & 0.82 & 0.76 & 0.75 \\
\hline $\mathrm{Cl}(\%)$ & 1.49 & 0.91 & 0.81 & 0.74 & 0.61 & 0.53 \\
\hline $\begin{array}{c}\text { Bulk Density } \\
\left(\mathrm{kg} / \mathrm{m}^{3}\right)\end{array}$ & 630.04 & 837.98 & 823.26 & 805.04 & 803.69 & 769.15 \\
\hline $\begin{array}{c}\text { Fines } \\
\text { Content (\%) }\end{array}$ & 0.08 & 0.07 & 0.07 & 0.13 & 0.18 & 0.19 \\
\hline
\end{tabular}

Initially both HHV and LHV of the FPMS pellet showed much lower values compared to the sawdust pellet. The variations in the heating value are shown in Figs. 1, 2, and 3. The calorific values of FPMS pellets were greatly improved according to the amount of the ion-refined oil mixed with FPMS (Fig. 1). When the mixing ratio of the sawdust in FPMS was increased to $50 \%$, a calorific value of approximately $12 \mathrm{MJ} / \mathrm{kg}$ was obtained, but it was lower than $14 \mathrm{MJ} / \mathrm{kg}$ in $30 \%$ of the ion-refined oil (Fig. 2). When the ion-refined oil was added under the condition that the mixing ratio of FPMS and sawdust was 50:50, the heating value equivalent to that of the sawdust pellet could be obtained from the $15 \%$ mixing ratio (Fig. 3).

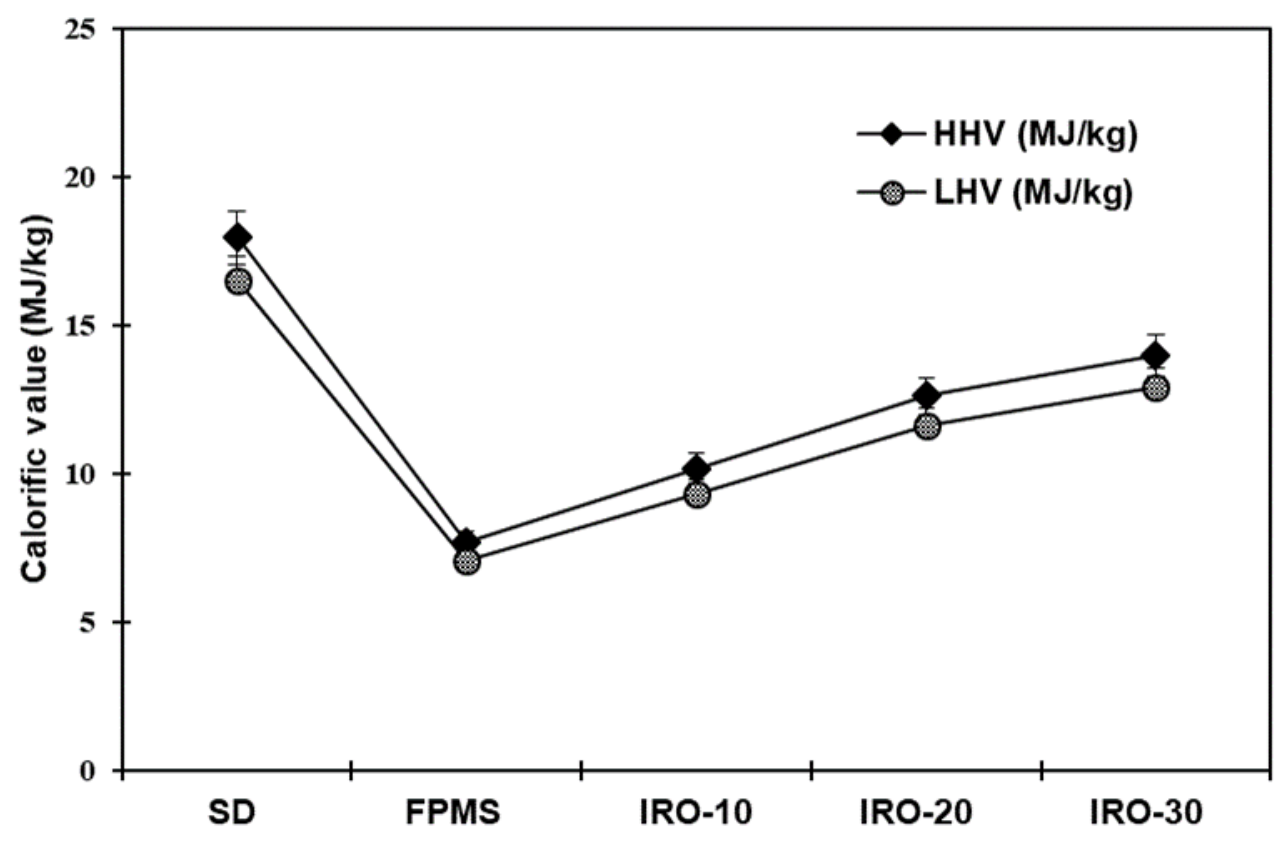

Fig. 1. Effect of ion-refined oil on the calorific value of FPMS pellets without sawdust 


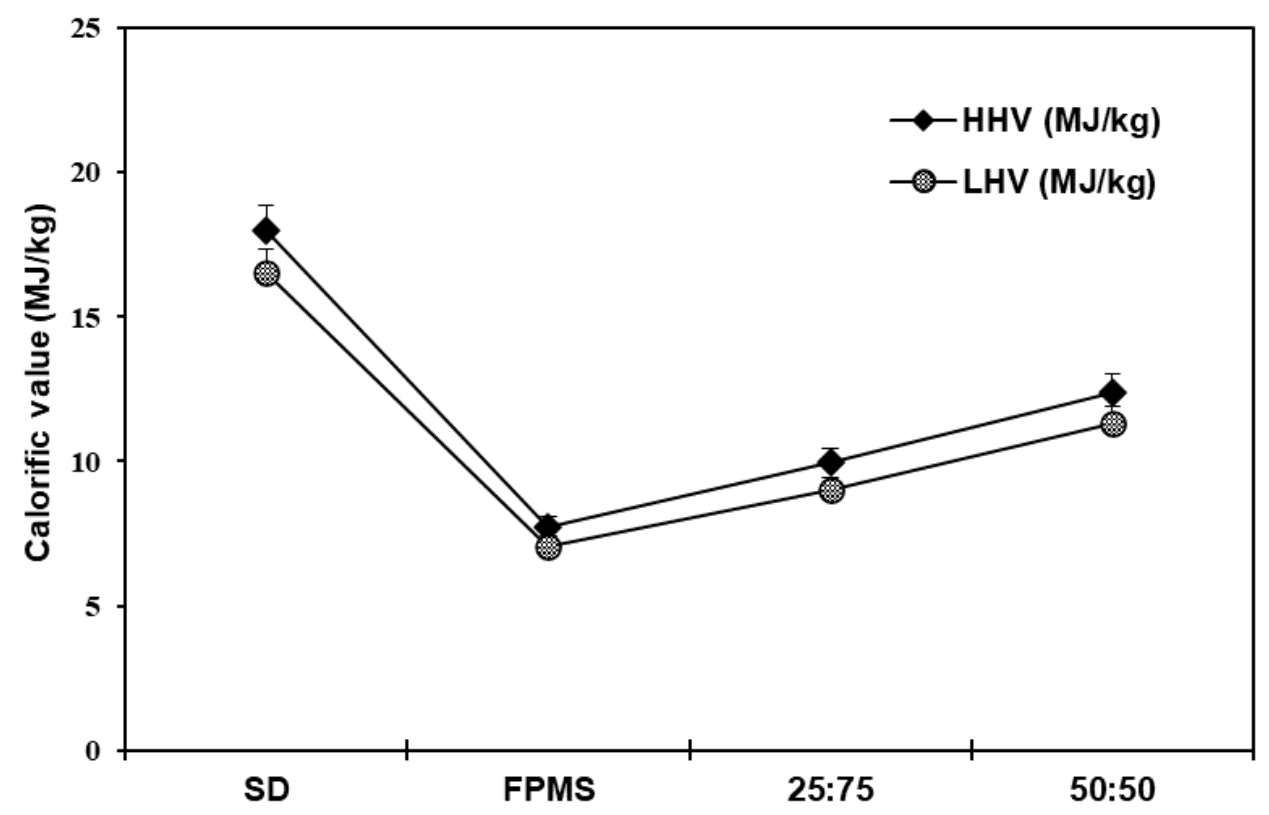

Fig. 2. Effect of sawdust on the calorific value of FPMS pellets without ion-refined oil

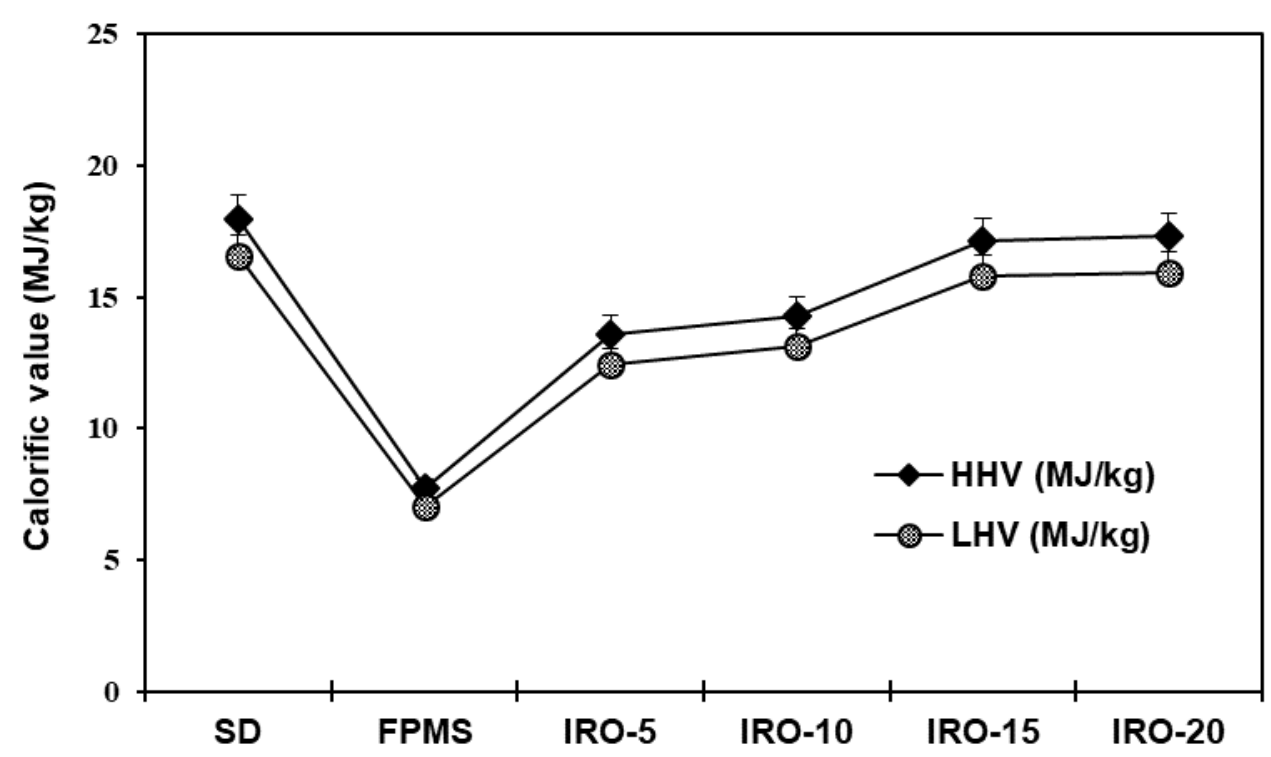

Fig. 3. Effect of ion-refined oil on the calorific value of pellets prepared from FPMS and sawdust mixed at 50:50

The dosage of the ion-refined oil was limited to $20 \%$ due to loss of mechanical durability of the final pellets (Figs. 4 and 6). In contrast, the addition of the sawdust to FPMS had little effect on the durability of the pellets (Fig. 5). According to the standard market demand, pellet durability must be $97.5 \%$ or higher. High mechanical durability of solid fuels is an important unit factor for storage capacity and transportation from production plant to repository. The high viscosity of the ion-refined oil weakened the bonding capacity of fine particles of FPMS during pelletization and eventually generated the fine particles. According to the ISO 3310-2 (2013), the fines content must be lower than or equal to $0.8 \%$. The increasing tendency of the fines content is shown in Tables 3 and 5. Unlike sawdust, which was a positive factor in improving the mechanical durability 
of pellets (Table 4), ion-refined oil could be a negative factor in the bonding strength of FPMS particles, so it is necessary to be careful when determining its mixing ratio.

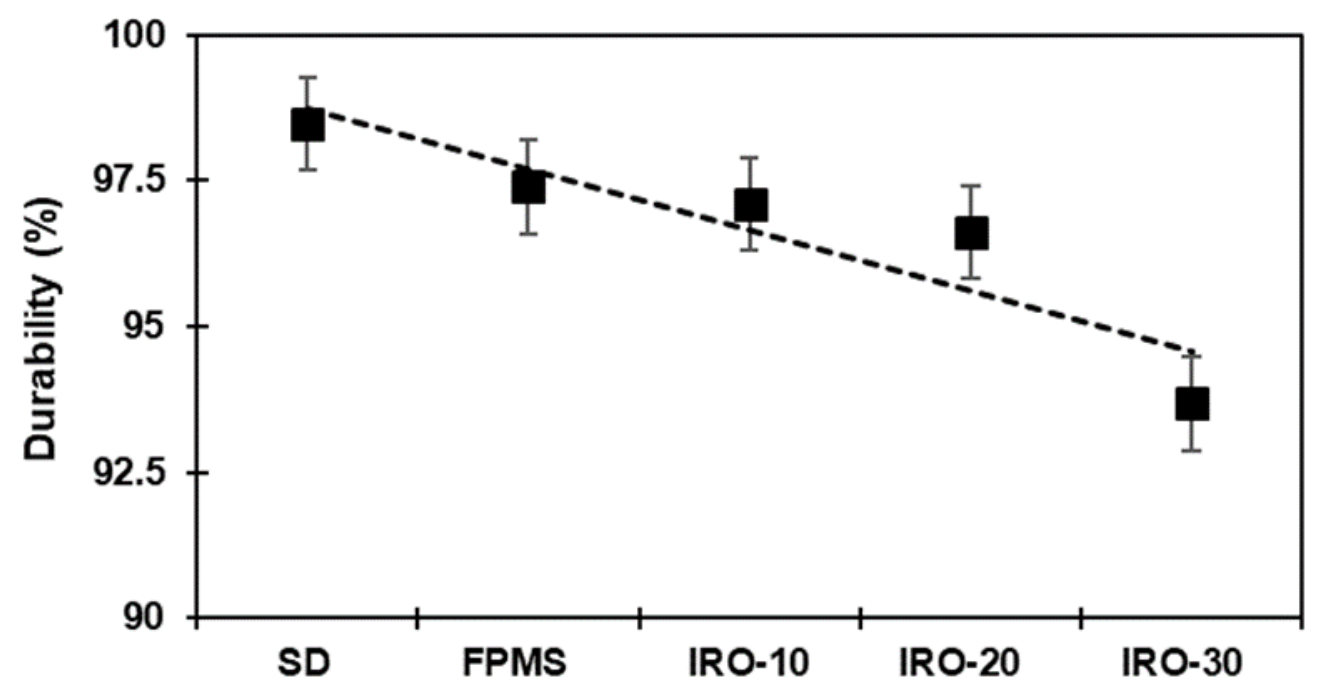

Fig. 4. Effect of ion-refined oil on durability of FPMS pellets

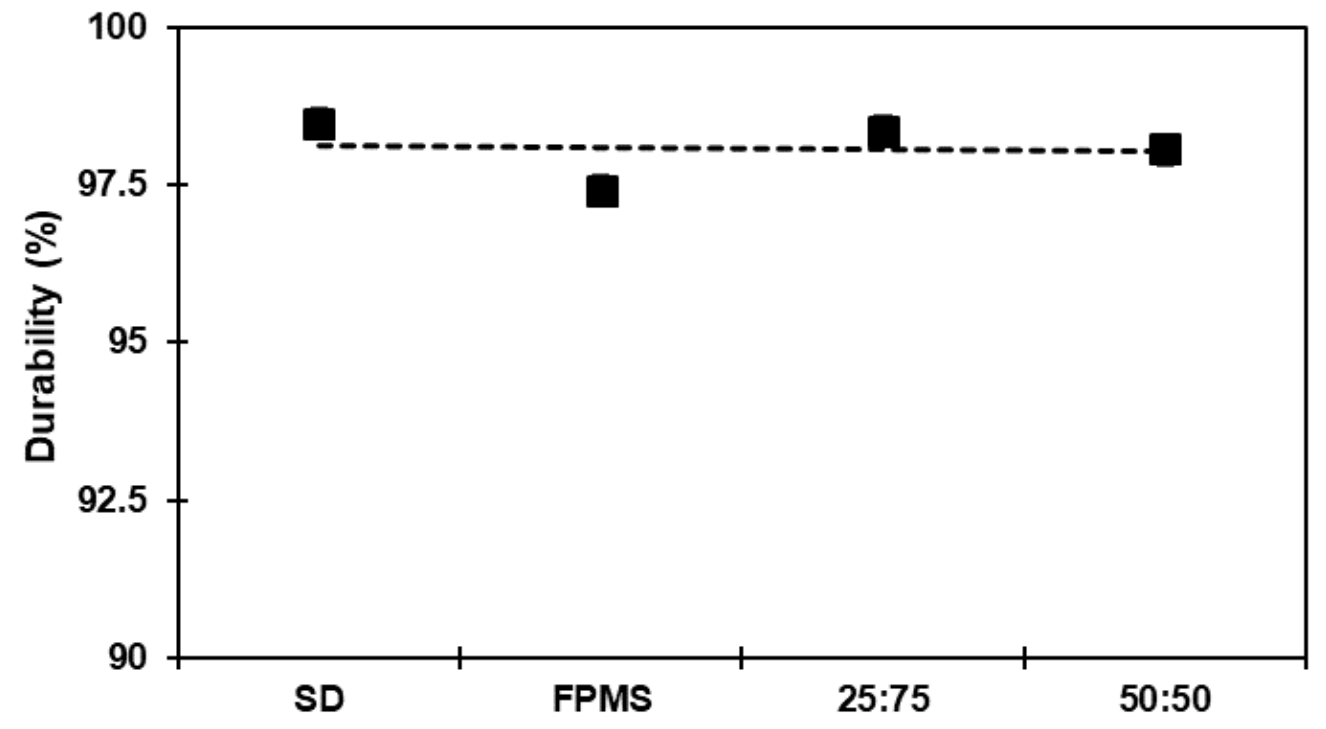

Fig. 5. Effect of sawdust on durability of FPMS pellets

Ignition and combustion are parts of a complicated process that are commonly seen as physicochemical changes occurring in the fuel pellets through thermal decomposition at a certain stage and time (Jittabut 2015). A single pellet made from FPMS as the main raw material was burned for $1 \mathrm{~min}$. As shown in Table 6, the burning experiment showed that pure FPMS pellets had a longer ignition time and a shorter combustion duration compared to the sawdust pellets. However, as the ion-refined oil was mixed, the ignition time was shorter, and the combustion duration was longer than that of pure FPMS pellets. However, FPMS pellets did not last as long as the sawdust pellets due to their excessive ash contents even when the ion-refined oil was mixed. Based on the results of $\mathrm{C}-1$, it was considered 
that volatile organic substances, such as aldehydes, ketones, and light hydrocarbons in the ion-refined oil, might have a great effect on shortening the ignition time and lengthening the combustion time of the prepared FPMS pellets.

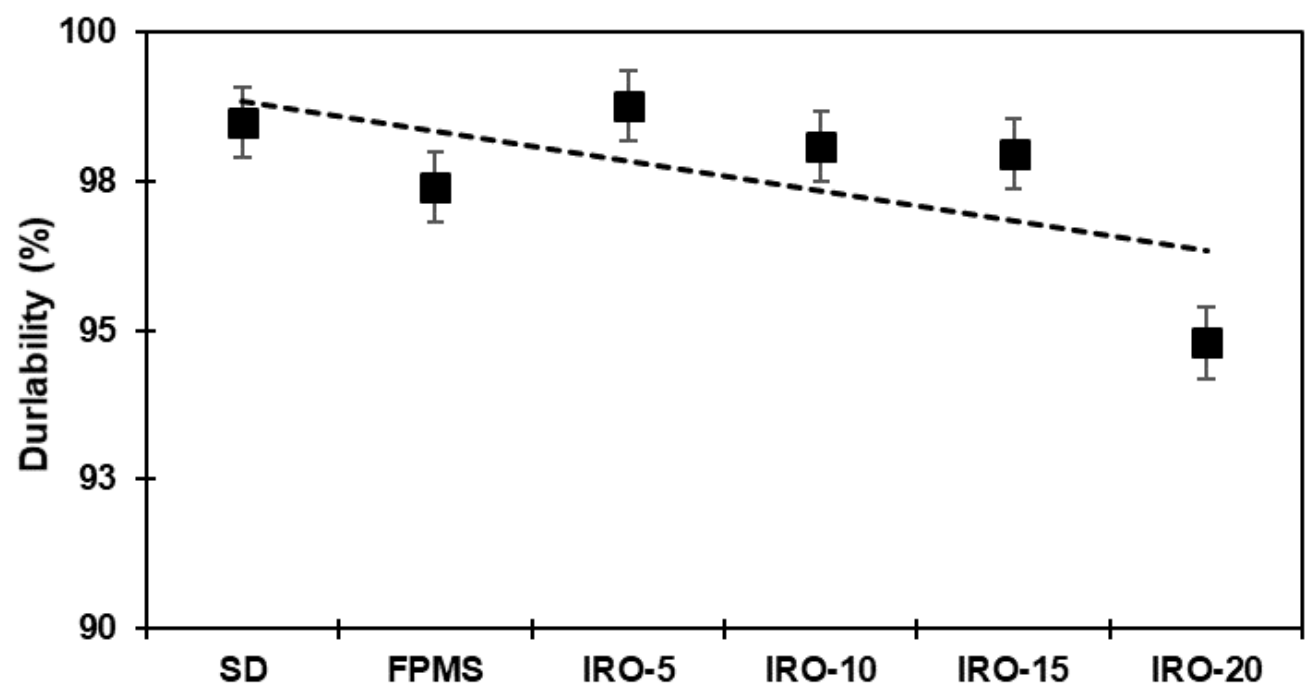

Fig. 6. Effect of ion-refined oil on durability of pellets prepared from FPMS and sawdust mixed at 50:50

Table 6. Effect of Ion-refined Oil on Ignition and Combustion of FPMS

\begin{tabular}{|c|c|c|c|c|c|}
\hline & SD & FPMS & IRO-10 & IRO-20 & IRO-30 \\
\hline \multirow{2}{*}{ C-1 } & & & & & \\
& & & & & \\
\hline
\end{tabular}

Table 7 illustrates the results of C-2 FPMS with sawdust to evaluate the ignition and combustion time. Wood sawdust contains carbon compounds, lignin, cellulose, hemicellulose, phenolic compounds, volatile compounds, and mineral contents, which help to decrease ignition time and increase combustion time (Kucuk and Aktepe 2017). The pellets prepared by mixing FPMS and sawdust at 50:50 were the most encouraging condition in terms of ignition time and combustion time when compared to pellets made only with FPMS. Although the sawdust was mixed up to $50 \%$, the ignition time was as short as that of the sawdust pellets, but the combustion duration was still only approximately half that of the sawdust pellets. If the ash content contained in FPMS was kept high, it was not easy to lengthen the combustion time. Table 8 compares the effects on the ignition time and combustion time of pellets when the ion refined oil was mixed with the raw materials with a specific mixing ratio. Even if only $5 \%$ of the ion-refined oil 
was mixed, the ignition time became the same as that of the sawdust pellets, and when $10 \%$ or more was mixed, the ignition time became shorter and the burning duration became longer than that of the sawdust pellets. In conclusion, it was found that it was difficult to use FPMS pellets as fuel due to their high ash contents. Therefore, to maximize the fuel efficiency of FPMS pellets, it was necessary to mix lignocellulosic biomass and organic solvents, such as ion-refined oil, in FPMS to reduce the ash content of the pellets and have a positive effect on ignition and combustion times.

Table 7. Effect of Sawdust on Ignition and Combustion of FPMS Pellets

\begin{tabular}{|c|c|c|c|c|}
\hline & SD & FPMS & $25: 75$ & $50: 50$ \\
\hline C-2 & & & & \\
& & & & \\
\hline Ignition (s) & 10 & 24 & 16 & 11 \\
\hline $\begin{array}{c}\text { Combustion } \\
\text { (s) }\end{array}$ & 108 & 5 & 32 & 51 \\
\hline
\end{tabular}

Table 8. Effect of Ion-refined Oil on Ignition and Combustion of Pellets Prepared from FPMS and Sawdust Mixed at 50:50

\begin{tabular}{|c|c|c|c|c|c|c|}
\hline & SD & FPMS & IRO-5 & IRO-10 & IRO-15 & IRO-20 \\
\hline \multicolumn{7}{|l|}{$C-3$} \\
\hline Ignition (s) & 10 & 24 & 10 & 9 & 7 & 4 \\
\hline Combustion (s) & 108 & 5 & 81 & 104 & 118 & 130 \\
\hline
\end{tabular}

\section{CONCLUSIONS}

1. This study investigated the pelletization of fine paper mill sludge (FPMS) with sawdust and ion-refined oil. Detailed characterizations were determined for the raw materials and the pellets produced. The effects of ion-refined oil on the heating value, ash content, ignition and combustion, and physical properties of the fuel pellets were examined. The FPMS had a lesser higher heating value after perfectly drying due to high ash content that stemmed from $\mathrm{CaCO}_{3}$.

2. When sawdust and ion-refined oil were mixed with FPMS, it was possible to increase the calorific values while reducing the ash contents of the pellets. It was confirmed that, when ionic refined oil was added to the raw material in which FPMS and sawdust were mixed at 50:50, the calorific values of the pellets were improved to that of wood pellets. 
3. The FPMS pellet was not satisfied with the ignition time and combustion duration but mixing ionic refined oil and sawdust in FPMS was effective in shortening the ignition time and increasing the combustion time. However, because excessive addition of the ion-refined oil was negative for the durability of the pellets, it was desirable to add less than $20 \%$.

4. The pelletization of FPMS using auxiliary raw materials, such as ion-refined oil and sawdust, is expected to be of great help in environmentally friendly disposal to papermakers' sludge treatment.

\section{ACKNOWLEDGEMENTS}

This work was supported by the Program for Forest Convergence Professional Manpower Promotion, funded by Korea Forest Service in 2020 (FTIS Grant No. 2020186A00-2022-AA02).

\section{REFERENCES CITED}

Abdullah, R., Ishak, C. F., Kadir, W. R., and Bakar, R. A. (2016). "Application of raw and composted recycled paper mill sludge on the growth of Khaya senegalensis and their effects on soil nutrients and heavy metals," Int. J. Agric. Biol. 18(1), 52-60.

DOI: $10.17957 / \mathrm{IJAB} / 15.0061$

Adeeyo, O. A., Oresegun, O. M., and Oladimeji, T. E. (2015). "Compositional analysis of lignocellulosic materials: Evaluation of an economically viable method suitable for woody and non-woody biomass," American Journal of Engineering Research 4(4), 14-19.

ASTM D1102-84 (2013). "Standard test method for ash in wood," ASTM International, West Conshohocken, PA, USA.

ASTM D3175-20 (2020). "Standard test method for volatile matter in the analysis sample of coal and coke," ASTM International, West Conshohocken, PA, USA.

ASTM D5373-16 (2016). "Standard test methods for determination of carbon, hydrogen and nitrogen in analysis samples of coal and carbon in analysis samples of coal and coke," ASTM International, West Conshohocken, PA, USA.

ASTM E871-82 (2019). "Standard test method for moisture analysis of particulate wood fuels," ASTM International, West Conshohocken, PA, USA.

ASTM E2618-13 (2019). "Standard test method for measurement of particulate emissions and heating efficiency of solid fuel-fired hydronic heating appliances," ASTM International, West Conshohocken, PA, USA.

Bae, J. H., and Kwon, S. D. (2006). "Recycling technologies of waste lubricating oils and their promotion policies in korea and foreign countries," Clean Technology 12(3), 113-127.

Basu, P. (2010). Biomass Gasification and Pyrolysis, $1^{\text {st }}$ Edition, Elsevier, Amsterdam, Netherlands.

Berghel, J., Frodeson, S., Granström, K., Renström, R., Ståhl, M., Nordgren, D., and Tomani, P. (2013). "The effects of kraft lignin additives on wood fuel pellet quality, energy use and shelf life," Fuel Process Technology 112, 64-69. DOI: 
10.1016/j.fuproc.2013.02.011

Bridjanian, H., and Sattarin, M. (2006). "Modern recovery methods in used oil rerefining," Petroleum \& Coal 48(1), 40-43. DOI: 10.1080/10916466.2019.1704782

Budzyń, S., and Tora, B. (2016). "Biomass fuel based on wastes from the paper industry," in: E3S Web of Conferences 10(2016), Article Number 00083. DOI: $10.1051 / \mathrm{e} 3$ sconf/20161000083

Carroll, J. P., and Finnan, J. (2012). "Physical and chemical properties of pellets from energy crops and cereal straws," Biosystem Engineering 112(2), 151-159. DOI: 10.1016/j.biosystemseng.2012.03.012

Chandrasekaran, S. R., Hopke, P. K., Rector, L., Allen, G., and Lin, L. (2012). "Chemical composition of wood chips and wood pellets," Energy \& Fuels 26(8), 4932-4937. DOI: $10.1021 / \mathrm{ef} 300884 \mathrm{k}$

Coimbra, R. N., Paniagua, S., Escapa, C., Calvo, L. F., and Otero, M. (2015). "Combustion of primary and secondary pulp mill sludge and their respective blends with coal: A thermogravimetric assessment," Renewable Energy 83, 1050-1058. DOI: 10.1016/j.renene.2015.05.046

Demirbaş, A. (2001). "Relationships between lignin contents and heating values of biomass," Energy Conversion and Management 42(2), 183-188. DOI: 10.1016/S0196-8904(00)00050-9

Demirbas, A. (2007). "Combustion of biomass," Energy Sources, Part A. Recovery, Utilization, and Environmental Effects 29(6), 549-561. DOI: 10.1080/009083190957694

Gravalos, I., Kateris, D., Xyradakis, P., Gialamas, T., Loutridis, S., Augousti, A., and Tsiropoulos, Z. (2010). "A study on calorific energy values of biomass residue pellets for heating purposes," in: Proceedings on Forest Engineering: Meeting the Needs of the Society and the Environment, Padova, Italy, pp. 1-9.

ISO 3310-2 (2013). "Test sieves - Technical requirements and testing - Part 2: Test sieves of perforated metal plate," International Organization for Standardization, Geneva, Switzerland.

ISO 17828 (2015). "Solid biofuels - Determination of bulk density," International Organization for Standardization, Geneva, Switzerland.

ISO 17830 (2016). Solid biofuels - Particle size distribution of disintegrated pellets, International Organization for Standardization, Geneva, Switzerland.

ISO 17831-1 (2015). "Solid biofuels - Determination of mechanical durability of pellets and briquettes," International Organization for Standardization, Geneva, Switzerland.

Jenkins, B. M., Baxter, L. L., and Miles, T. R. (1998). "Combustion properties of biomass," Fuel Processing Technology 54(1-3), 17-46. DOI: 10.1016/S03783820(97)00059-3.

Jittabut, P. (2015). "Physical and thermal properties of briquette fuels from rice straw and sugarcane leaves by mixing molasses," Energy Procedia 79, 2-9. DOI: 10.1016/j.egypro.2015.11.452.

Kang, K., Qiu, L., Zhu, M., Sun, G., Wang, Y., and Sun, R. (2018). "Codensification of agroforestry residue with bio-oil for improved fuel pellets," Energy \& Fuels 32(1), 598-606. DOI: 10.1021/acs.energyfuels.7b03482.

Kucuk, O., and Aktepe, N. (2017). "Effect of phenolic compounds on the flammability in forest fires," International Journal of Engineering Sciences \& Research Technology 6(4), 320-327. DOI: 10.5281/zenodo.546647

Lee, J. Y., Kim, C. H., Kown, S., and Park, H. H. (2017). "Effect of composting of paper 
mill sludge for land spreading," Nordic Pulp \& Paper Research Journal 32(4), 691698. DOI: 10.3183/npprj-2017-32-04_p691-698_kim.

Lehtikangas, P. (2001). "Quality properties of pelletised sawdust, logging residues and bark," Biomass and Bioenergy 20(5), 351-360. DOI:10.1016/S0961-9534(00)00092-1.

Likon, M., and Trebše, P. (2012). "Recent advances in paper mill sludge management," in: Industrial Waste, K. Y. Show (ed.), InTech Open, Rijeka, Croatia, pp. 73-90.

Lindström, E., Larsson, S. H., Boström, D., and Öhman, M. (2010). "Slagging characteristics during combustion of woody biomass pellets made from a range of different forestry assortments," Energy \& Fuels 24(6), 3456-3461. DOI: 10.1021/ef901571c

Matúš, M., Križan, P., Šooš, L., and Beniak, J. (2018). "The effect of papermaking sludge as an additive to biomass pellets on the final quality of the fuel," Fuel 219, 196-204. DOI: 10.1016/j.fuel.2018.01.089.

Misljenovic, N., Mosbye, J., Schüller, R. B., Lekang, O. I., and Salas Bringas, C. (2014). "The effect of waste vegetable oil addition on pelletability and physical quality of wood pellets," Annual Transactions of The Nordic Rheology Society 22, 211-218.

Mock, C., Lee, H., Choi, S. C., Yang, W., Choi, S., and Manovic, V. (2018). "Combustion behavior of single pellets of coal-wood mixtures in a hot gas flow field," Energy \& Fuels 32(11), 11913-11923. DOI: 10.1021/acs.energyfuels.8b02557

Monte, M. C., Fuente, E., Blanco, A., and Negro, C. (2009). "Waste management from pulp and paper production in the European Union," Waste Management 29(1), 293308. DOI: 10.1016/j.wasman.2008.02.002

Narra, S., Tao, Y., Glaser, C., Gusovius, H. J., and Ay, P. (2010). "Increasing the calorific value of rye straw pellets with biogenous and fossil fuel additives," Energy \& Fuels 24(9), 5228-5234. DOI: 10.1021/ef100823b

Nosek, R., Holubcik, M., Jandacka, J., and Radacovska, L. (2017). "Analysis of paper sludge pellets for energy utilization," BioResources 12(4), 7032-7040. DOI: 10.15376/biores.12.4.7032-7040

Obernberger, L., and Thek, G. (2004). "Physical characterisation and chemical composition of densified biomass fuels with regard to their combustion behavior," Biomass and Bioenergy 27(6), 653-669. DOI: 10.1016/j.biombioe.2003.07.006

Oh, J. H., Hwang, J. S., and Cha, D. S. (2014). "Fuel properties of woody pellets in domestic markets of Korea," Journal of Forest and Environmental Science 30(4), 362-369. DOI: 10.7747/jfes.2014.30.4.362

Poddar, S., Kamruzzaman, M., Sujan, S. M. A., Hossain, M., Jamal, M. S., Gafur, M. A., and Khanam, M. (2014). "Effect of compression pressure on lignocellulosic biomass pellet to improve fuel properties: Higher heating value," Fuel 131, 43-48. DOI: 10.1016/j.fuel.2014.04.061

Siddiqui, M. T. H., Nizamuddin, S., Mubarak, N. M., Shirin, K., Aijaz, M., Hussain, M., and Baloch, H. A. (2019). "Characterization and process optimization of biochar produced using novel biomass, waste pomegranate peel: A response surface methodology approach," Waste and Biomass Valorization 10(3), 521-532. DOI: 10.1007/s12649-017-0091-y

Sommersacher, P., Brunner, T., and Obernberger, I. (2012). "Fuel indexes: A novel method for the evaluation of relevant combustion properties of new biomass fuels," Energy \& Fuels 26(1), 380-390. DOI: 10.1021/ef201282

SWP-846 (1994). "Bomd preparation method for solid waste," U.S. Environmental 
Protection Agency, Washington D.C., USA.

TAPPI T203 cm-99 (1999). "Alpha-, beat-and gamma-cellulose in pulp," TAPPI Press, Atlanta, GA, USA.

Tarasov, D., Shahi, C., and Leitch, M. (2013). "Effect of additives on wood pellet physical and thermal characteristics: A review," International Scholarly Research Notices 2013, Article ID 876939. DOI: 10.1155/2013/876939

Toscano, G., Riva, G., Foppa Pedretti, E., Corinaldesi, F., Mengarelli, C., and Duca, D. (2013). "Investigation on wood pellet quality and relationship between ash content and the most important chemical elements," Biomass and Bioenergy 56, 317-322. DOI: 10.1016/j.biombioe.2013.05.012

Ward, B. J., Yacob, T. W., and Montoya, L. D. (2014). "Evaluation of solid fuel char briquettes from human waste," Environmental Science Technology 48(16), 98529858. DOI: 10.1021/es500197h

Zevenhoven, M., Yrjas, P., Skrifvars, B. J., and Hupa, M. (2012). "Characterization of ash-forming matter in various solid fuels by selective leaching and its implications for fluidized-bed combustion," Energy \& Fuels 26(10), 6366-6386. DOI: $10.1021 /$ ef300621j

Article submitted: September 23, 2020; Peer review completed: November 26, 2020; Revised version received and accepted: December 1, 2020; Published: December 21, 2020. DOI: 10.15376/biores.16.1.1144-1160 